\title{
Phosphorylation of Cofilin Regulates Extinction of Conditioned Aversive Memory via AMPAR Trafficking
}

\author{
Yue Wang, ${ }^{1 \star}$ Qing Dong, ${ }^{1,2 \star}$ Xu-Feng Xu, ${ }^{1}$ Xuan Feng, ${ }^{1}$ Jian Xin, ${ }^{1}$ Dong-Dong Wang, ${ }^{1}$ Hui Yu, ${ }^{1}$ Tian Tian, ${ }^{1}$ and \\ Zhe-Yu Chen ${ }^{1}$ \\ 'Department of Neurobiology, Shandong Provincial Key Laboratory of Mental Disorders, School of Medicine, Shandong University, Jinan, Shandong \\ 250012, People's Republic of China, and ²Department of Neurology, Third Affiliated Hospital of Sun Yat-sen University, Guangzhou, Guangdong 510630, \\ People's Republic of China
}

Actin dynamics provide an important mechanism for the modification of synaptic plasticity, which is regulated by the actin depolymerizing factor (ADF)/cofilin. However, the role of cofilin regulated actin dynamics in memory extinction process is still unclear. Here, we observed that extinction of conditioned taste aversive (CTA) memory led to temporally enhanced ADF/cofilin activity in the infralimbic cortex (IrL) of the rats. Moreover, temporally elevating ADF/cofilin activity in the IrL could accelerate CTA memory extinction by facilitating AMPAR synaptic surface recruitment, whereas inhibition of ADF/cofilin activity abolished AMPAR synaptic surface trafficking and impaired memory extinction. Finally, we observed that ADF/cofilin-regulated synaptic plasticity was not directly coupled to morphological changes of postsynaptic spines. These findings may help us understand the role of ADF/cofilin-regulated actin dynamics in memory extinction and suggest that appropriate manipulating ADF/cofilin activity might be a suitable way for therapeutic treatment of memory disorders.

\section{Introduction}

Actin is highly enriched in dendritic spines and provides the structural foundation for spine formation, morphological properties, and motility associated with synaptic modification (Matus, 2000; Carlisle and Kennedy, 2005; Hotulainen and Hoogenraad, 2010). Furthermore, actin dynamics are critically involved in postsynaptic receptor specializations and synaptic plasticity, including long-term potentiation (LTP), a form of synaptic plasticity considered critical to learning and memory formation (Zhou et al., 2001; Meng et al., 2002; Bramham, 2008; Gu et al., 2010; Rust et al., 2010). Therefore, actin remodeling provides an important mechanism for the regulation of synaptic structure and function. Previous studies have reported that actin dynamics in the amygdala and dorsal hippocampus are required for memory acquisition and consolidation (Hou et al., 2009; Mantzur et al., 2009). We also showed that actin rearrangement was related with synaptic structure plasticity during conditioned

Received Oct. 31, 2012; revised Feb. 19, 2013; accepted March 5, 2013.

Author contributions: Y.W. and Z.-Y.C. designed research; Y.W., Q.D., X.-F.X., X.F., J.X., D.-D.W., H.Y., and T.T. performed research; Y.W. and Q.D. analyzed data; Y.W., Q.D., and Z.-Y.C. wrote the paper.

This work was supported by the National Natural Science Foundation of China (Grants 31130026 and 31070991 ), the National 973 Basic Research Program of China (Grants 2012 CB911000 and 2010CB912004), the State Program of the National Natural Science Foundation of China for Innovative Research Group (Grant 81021001), the Foundation for Excellent Young Scientists of Shandong Province (Grant BS2011SW021), and the Independent Innovation Foundation of Shandong University.

*Y.W. and Q.D. contributed equally to this work.

The authors declare no competing financial interests.

Correspondence should be addressed to Dr. Zhe-Yu Chen, Department of Neurobiology, School of Medicine, Shandong University, 44 Wenhua Xi Road, Jinan, Shandong 250012, People's Republic of China. E-mail: zheyuchen@sdu.edu.cn.

DOI:10.1523/JNEUROSCI.5107-12.2013

Copyright $\odot 2013$ the authors $\quad 0270-6474 / 13 / 336423-11 \$ 15.00 / 0$ taste aversion (CTA) memory formation (Bi et al., 2010). Similar to memory formation, memory extinction is considered a new form of learning. Fischer et al. (2004) reported that actin rearrangement in the hippocampus is essential for the extinction of contextual fear memory. However, the detailed mechanism underlying actin dynamics in memory extinction has been less studied.

Actin depolymerizing factor (ADF)/cofilin play an important role in actin dynamics and rearrangement by severing and depolymerizing actin filaments at their pointed ends (Bamburg, 1999; Bernstein and Bamburg, 2010). The activities of cofilin are reversibly regulated by phosphorylation (inactivation) and dephosphorylation (activation) at its serine-3 (Ser3) residue (Agnew et al., 1995; Endo et al., 2003). Cofilin is mainly phosphorylated by LIM kinases (LIMKs) and dephosphorylated by Slingshot (SSH) phosphatase (Van Troys et al., 2008). Cofilin phosphorylation and dephosphorylation have been associated with spine morphology alteration, as well as postsynaptic trafficking and membrane addition of AMPARs during synaptic plasticity (Chen et al., 2007; Carlisle et al., 2008; Gu et al., 2010; Yuen et al., 2010). limk-1 knock-out mice displayed increased cofilin activity that leads to immature spines with reduced size, although it enhanced LTP (Meng et al., 2002), suggesting that cofilin may regulate synaptic potentiation via mechanisms distinct from those that control spine morphology.

The role of cofilin regulated actin dynamics in synaptic plasticity has been well established in cultured neurons and brain slices (Fukazawa et al., 2003; Gu et al., 2010; Yuen et al., 2010; Zhou et al., 2011); however, the in vivo relevance of cofilinmediated actin dynamics for learning and memory has largely remained elusive. A recent paper has shown that forebrain- 
specific loss of cofilin leads to associative learning impairment (Rust et al., 2010); however, whether the phosphorylation status of cofilin affects the memory extinction process is still unclear. It has been reported that the infralimbic cortex (IrL) plays a unique role in memory extinction. In this study, we try to investigate whether the cofilin-mediated actin dynamics in the IrL play a role in memory extinction and its underlying mechanism.

\section{Materials and Methods}

Animals. Male Wistar rats weighing 250-280 g were used in the study (Vital River Laboratories). Rats were housed individually at $22 \pm 2^{\circ} \mathrm{C}$ under $12 \mathrm{~h}$ light/dark cycles. Water and food were available ad libitum except where otherwise noted. All experiments conformed to the National Institutes of Health Guide for the Care and Use of Laboratory Animals and were approved by the Institutional Animal Care and Use Committees of Shandong University.

Reagents and antibodies. In our experiments, we used the peptidomimetic method to alter endogenous cofilin activity and GluA2-related AMPAR membrane trafficking. All peptides were synthesized and purified by GL Biochem. Peptides containing a 16 aa sequence of the cofilin Ser3 site (MASGVAVSDGVIKVFN, referred to as S3 peptides) or phosphor-Ser3 site [MAS(p)GVAVSDGVIKVFN, referred to as pS3 peptides] were used to inhibit LIMKs or SSH, respectively (Aizawa et al., 2001; Toda et al., 2006; Gu et al., 2010). Peptides containing a 10 aa sequence (KAMKVAKNPQ, referred to as pepR845A peptides), which mimics the $N$-ethylmaleimide-sensitive factor (NSF)-binding site in GluA2, were used to interfere with the interaction between NSF and GluA2 (Joels and Lamprecht, 2010). These peptides were fused to a Tatlike polyarginine membrane permeability sequence (GRRRRRRRRRRR) to facilitate its entrance into cells and to a biotin molecule to allow detection. Tat-like peptide (Biotin-GRRRRRRRRRRR) was used as a control, named Tat.

Antibodies to cofilin, phosphorylated cofilin (p-cofilin), LIMK1, p-LIMK1, and GluA3 were purchased from Cell Signaling Technology, SSH1L and p-SSH1L from ECM Biosciences, GluA1, GluA2, and GluA4 from Abcam, NR1 from Millipore, and the other antibodies and regents were from Sigma-Aldrich.

CTA acquisition and extinction. The behavioral protocol of CTA was performed according to previously published protocols (Berman et al., 2003). In brief, saccharin $(0.1 \% \mathrm{w} / \mathrm{v}$, sodium salt) was used as an unfamiliar taste (conditioned stimulus, CS), and intraperitoneal injection of $\mathrm{LiCl}(0.15 \mathrm{M}, 2 \%$ body weight $)$ was the malaise-inducing agent [unconditioned stimulation (US)]. Rats were first subjected to $24 \mathrm{~h}$ of water deprivation and then pretrained to get their water ration once a day from two pipettes with $10 \mathrm{ml}$ of water each for $10 \mathrm{~min}$. They were trained $3 \mathrm{~d}$ to get their daily water ration. On the conditioning day, the rats were allowed to drink the saccharin solution (two pipettes with $10 \mathrm{ml}$ of saccharin each) instead of water for $10 \mathrm{~min}$. Forty minutes later, the rats were injected with $\mathrm{LiCl}$ intraperitoneally. On the next $2 \mathrm{~d}$, rats were presented with water for $10 \mathrm{~min}$ daily. On the third day after conditioning, rats were given an array of six pipettes randomly, three containing $5 \mathrm{ml}$ of water and three containing $5 \mathrm{ml}$ of saccharin, to determine the acquired aversion. The results were quantified by aversion indexes (AIs) (as a percentage $)=($ water intake $) /($ saccharin intake + water intake $) \times 100 \%$. Rats with AIs $<80 \%$ were excluded from the further extinction experiments. For extinction of CTA, the same multiple-choice test was repeated in the next $5 \mathrm{~d}$ without US stimulation, and the AIs were calculated.

Contextual fear conditioning and extinction. For conditioning, the rats were put into a standard fear-conditioning chamber (Panlab). After $120 \mathrm{~s}$ without any stimulation, they received three $0.8 \mathrm{~mA}, 1 \mathrm{~s}$ foot shocks through a stainless steel grid floor by a shock generator. The interval of foot shocks was $60 \mathrm{~s}$. Following the last shock, rats remained in the chamber for $60 \mathrm{~s}$ before being placed back to their home cages.

Extinction training was defined as the repetitive exposure to the CS (the chamber) without foot shock. Twenty-four hours after fear conditioning, rats were placed in the same context for 10 min unreinforced trial. The similar manner extinction training was performed on the next $2 \mathrm{~d}$. The levels of freezing within $10 \mathrm{~min}$ were evaluated using an analog signal which generated by the animal movement through a high sensitivity weight transducer system. After each session, the experimental context was cleaned with $70 \%$ ethanol. The peptides were administered immediately after the first and second extinction training.

Surgery and microinjection. Rats, anesthetized with $10 \%$ chloral hydrate $(0.3 \mathrm{ml}$ per $100 \mathrm{~g}$, i.p. $)$, were implanted bilaterally with guide cannulas (23 gauge) to the IrL. The coordinates were as follows: anteroposterior $(\mathrm{AP}),+3.15 \mathrm{~mm}$; lateral $(\mathrm{L}), \pm 0.5 \mathrm{~mm}$; dorsoventral $(\mathrm{V})$, $-3.7 \mathrm{~mm}$ (Paxions and Watson, 1996). A stylus was placed in the guide cannula to prevent clogging. One week after surgery, bilateral infusion cannulas ( 28 gauge) were inserted, extending $1.5 \mathrm{~mm}$ beyond the tip of the guide cannulas. The injection cannula was connected via PE20 tubing to a $10 \mu \mathrm{l}$ Hamilton microsyringe, driven by a microinjection pump (KDS 200, KD Scientific). Infusions were administered in a volume of 1 $\mu \mathrm{l}$ over $2 \mathrm{~min}$, and an additional $2 \mathrm{~min}$ was allowed for diffusion before the infusion cannulas were removed. Tat-S3, Tat-pS3 (dissolved in artificial CSF, $5 \mathrm{~nm}, 1 \mu \mathrm{l}$ per side) (Tada and Sheng, 2006), Tat-pepR845A (dissolved in artificial CSF, $50 \mu \mathrm{g} \mu \mathrm{l}^{-1}, 1 \mu \mathrm{l}$ per side) (Van Troys et al., 2008) and Tat-control were administered into the IrL immediately or $4 \mathrm{~h}$ after each extinction trial on 3 consecutive days.

Immunohistochemistry. After perfusion with $4 \%$ paraformaldehyde in PBS, rats were decapitated and the brains were removed and placed for postfixation in $30 \%$ sucrose in PBS. Brains were frozen and sliced (40 $\mu \mathrm{m})$. Slices were blocked and subjected to antiphospho-cofilin antibody in $2 \%$ normal goat serum (NGS) in PBS and incubated overnight at $4^{\circ} \mathrm{C}$. Slices were incubated with anti-rabbit Alexa Fluor 594 for $2 \mathrm{~h}$ at room temperature (RT). Photographs were taken using fluorescent microscopy (Nikon $80 \mathrm{i})$. Images were analyzed using Imaging computer program (NIS-Elements BR, Nikon).

Peptide localization in brain. Rats were anesthetized $30 \mathrm{~min}$ following microinjection with Tat-fused peptides and perfused as described above. After postfixation, brains were frozen and sliced $(40 \mu \mathrm{m})$. Slices were incubated with streptavidin-Alexa Fluor 488 in PBS at room temperature for $2 \mathrm{~h}$. Slices were examined using fluorescent microscopy (Nikon 80i) to verify the scope of solution diffusion and the microinfusion sites.

Rapid Golgi impregnation. The Golgi method described in this study was used in previous studies in our laboratory (Yu et al., 2009). Brains were rapidly isolated $30 \mathrm{~min}$ after different peptide treatment in the first extinction trial (E1) or the third extinction trial (E3), and conducted using FD rapid Golgi stain kit (FD Neuro Technologies). For spine density analysis, we referred to the method of previous reports (Magarinos et al., 2011). In brief, the dendritic segments were imaged under bright-field illumination on a Nikon $80 \mathrm{i}$ microscope with a $60 \times$ oil-immersion objective. Three to 5 dendritic segments of apical or basal dendrites, each at least $15 \mu \mathrm{m}$ in length, were analyzed per neuron, and 5 pyramidal neurons within layer II/III of the IrL were analyzed per brain. The number of spines per neurite segment was counted, and the length of neurite segments was measured by MetaMorph software (Molecular Devices). The maximal diameter of the spine, head, and the neck were measured by MetaMorph software from 100 spines of each brain randomly. Five rats were included per group.

Tissue preparation and Western blot analysis. Brains were quickly removed after decapitation at the desired time points. According to the atlas (Paxions and Watson, 1996), the IrL region were obtained freehand at $0^{\circ} \mathrm{C}$ from $1-\mathrm{mm}$-thick coronal slices and frozen in liquid nitrogen followed by homogenization or stored at $-80^{\circ} \mathrm{C}$ until further use. After grinding in ice-cold TNE buffer (10 mM Tris, pH8, $150 \mathrm{~mm} \mathrm{NaCl}, 1 \%$ NP-40, 1 mM EDTA with protease and phosphatase inhibitors). The samples were centrifuged at $16000 \times g$ for $15 \mathrm{~min}$ at $4^{\circ} \mathrm{C}$, and the supernatant was collected and eluted by boiling in lithium dodecyl sulfate (LDS) sample buffer (Invitrogen) for Western blot analysis. Protein content was detected using the BCA protein assay. Densitometry analysis on the bands was calculated using Quantity One (version 4.6.2, Bio-Rad).

Synaptoneurosome preparation. The IrL brain tissue of rat was harvested 30 min following E1 and E3, and synaptoneurosomes (SNSs) were essentially prepared according to the method as previously described (Villasana et al., 2006; Conboy and Sandi, 2010). Each rat's IrL tissue was homogenized in ice-cold homogenization buffer (10 mM HEPES, $0.5 \mathrm{~mm}$ DTT, 1.0 mм EDTA, 2.0 mм EGTA) containing protease and phospha- 

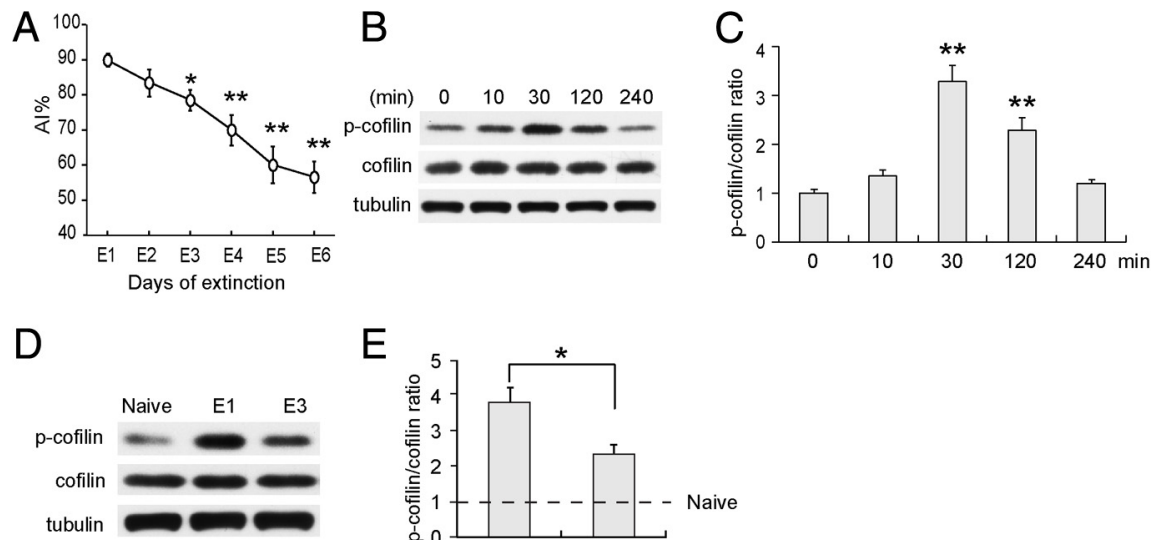

E
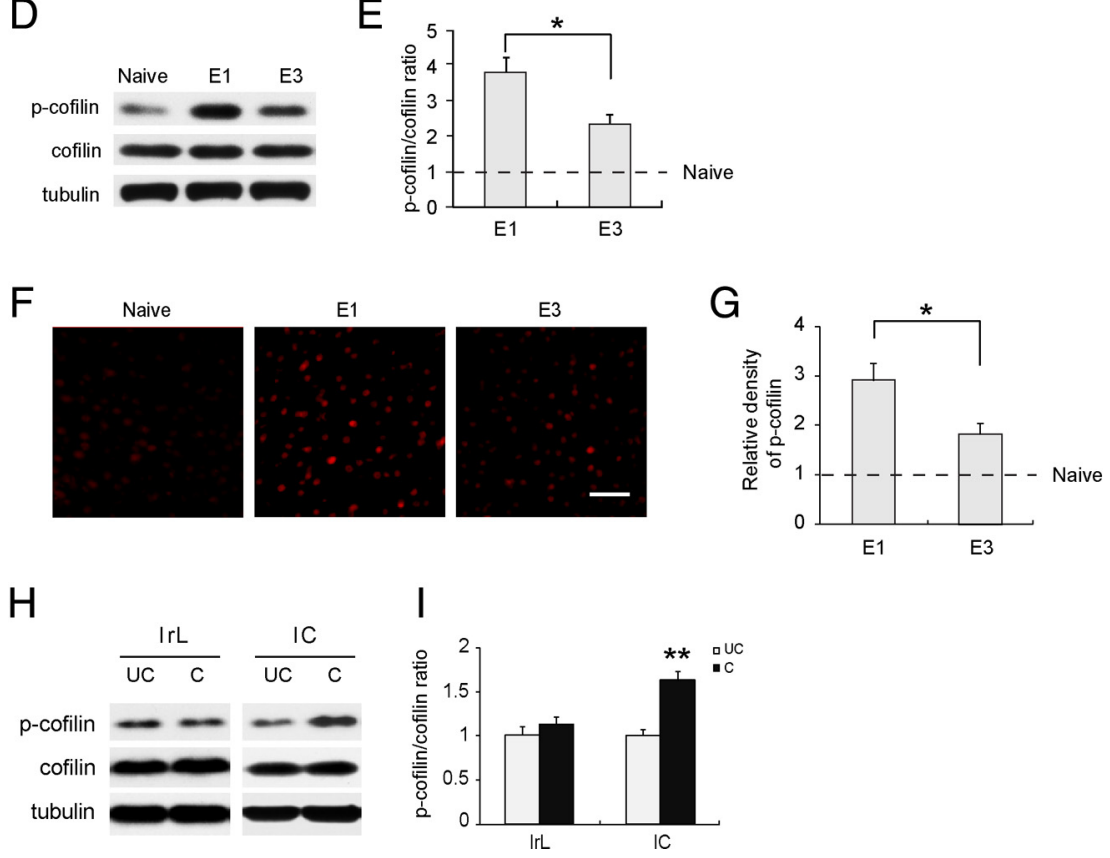

Figure 1. Successive extinction training increased cofilin activity in the IrL. $A$, The Als of rats decreased during CTA extinction. $n=10$ rats per extinction trial. ${ }^{*} p<0.05,{ }^{* *} p<0.01$, versus E1. $\boldsymbol{B}$, Representative immunoblots of $p$-cofilin (Ser3), total cofilin. and tubulin in the IrL at different time points after exposure to E1. C, Relative quantification of $\mathrm{p}$-cofilin/cofilin ratio. Zero minutes control is indicated at $1 . n=4-5$ rats per time point. ${ }^{* *} p<0.01$ versus 0 min. $D$, The IrL extracts were prepared 30 min after E1, $E 3$, or from naive rats and were analyzed for cofilin phosphorylation by immunoblotting. $E$, Relative quantification of p-cofilin/ cofilin ratio is shown. P-cofilin levels were significantly reduced after E3 compared with E1. Naive control is indicated at $1 . n=4$ rats. ${ }^{*} p<0.05$ versus $E 1$ group. $\boldsymbol{F}$, Representative images of immunofluorescent-stained $p$-cofilin in the IrL from the naive, $\mathrm{E} 1$, and $\mathrm{E} 3$ rats. Thirty minutes after $\mathrm{E} 1$ and $\mathrm{E} 3$, rats were perfused and followed by immunofluorescence staining. $G$, Relative quantification of the densities of $p$-cofilin immunofluorescent staining. $n=3$ rats. ${ }^{*} p<0.05$ versus E1 group. Naive control is indicated at $1 . \boldsymbol{H}$, Representative images of immunoblots of $p$-cofilin (Ser3), total cofilin, and tubulin in the IrL and IC at 30 min after CTA acquisition. $I$, Relative quantification of $p$-cofilin/cofilin ratio after acquisition is shown. $n=4-5$ rats. ${ }^{* *} p<0.01$ versus UC group. UC, Unconditioned (saline injection); C, conditioned (LiCl injection). All values are presented as the mean \pm SEM.

tase inhibitor mixture (Roche). Homogenates were then passed through two $100-\mu \mathrm{m}$-pore nylon mesh filters held in a 25 -mm-diameter filter holder, followed by two $5 \mu \mathrm{m}$-pore filters held in a 25 -mm-diameter filter holder. The resulting filtrates were centrifuged at $1000 \times g$ for 15 min at $4^{\circ} \mathrm{C}$. Resultant pellets that corresponded to the SNS were resuspended in $1 \%$ SDS, boiled for $10 \mathrm{~min}$, and stored at $-20^{\circ} \mathrm{C}$. Synaptic enrichment of the SNS fraction was confirmed using synaptophysin as presynaptic marker and PSD95 as postsynaptic marker. The samples were applied to quantify all synaptic protein contents (GluA1, GluA2, GluA3, GluA4, and NR1) in the experiment by Western blot analysis.

Cell-surface biotinylation. Cell-surface proteins were prepared from SNS according to the protocol previously described (Conboy and Sandi, 2010). One hundred and twenty micrograms of SNS were resuspended in $50 \mu \mathrm{l}$ of PBS, and then incubated in $200 \mu \mathrm{l}$ of $1.5 \mathrm{mg} \mathrm{of} \mathrm{ml}^{-1}$ sulfo-NHSSS-biotin moiety (Pierce) at $4^{\circ} \mathrm{C}$ for $30 \mathrm{~min}$ to biotinylated surface proteins. Unreacted biotin was then quenched and removed with $100 \mathrm{~mm}$ glycine in PBS. After centrifugation $\left(1000 \times \mathrm{g}, 10 \mathrm{~min}, 4^{\circ} \mathrm{C}\right)$, membranes were lysed in homogenization buffer containing 1\% SDS and protease and phosphatase inhibitor mixture (Roche). Biotinylated proteins were precipitated with $20 \mu \mathrm{l}$ of Pierce avidin agarose for $2 \mathrm{~h}$ at $4^{\circ} \mathrm{C}$. The agarose beads were precipitated by sequential centrifugation $(500 \times g, 3 \mathrm{~min})$ followed by three washing steps in homogenization buffer. After the final precipitation, washed beads were eluted 2 times with sample buffer and boiled for $10 \mathrm{~min}$ at $98^{\circ} \mathrm{C}$.

Postembedding immunogold method. Rats with different peptide treatment were deeply anesthetized 30 min after E1 or E3 with chloral hydrate and perfused transcardially with saline, followed by fixative (4\% paraformaldehyde with $0.1 \%$ glutaraldehyde in $0.01 \mathrm{~m} \mathrm{PBS}, \mathrm{pH}$ 7.4). The brain was removed quickly and coronal vibratome sections $(500 \mu \mathrm{m})$ containing the IrL were cut into cuboid blocks. To better estimate the electron microscope objective, each "big" block of the IrL was then divided into three "small" blocks. Freeze substitution and low-temperature embedding in Lowicryl was performed on the small blocks as previously reported (Adams et al., 2001). Ultrathin sections were obtained (65-70 $\mathrm{nm}$ thickness) and collected on Formvar-coated 200 mesh nickel grids. Four grids were made for every block. Specimens were incubated with $0.1 \%$ $\mathrm{NaBH}_{4}$ in PBS for 15-30 min. After washing with PBS, grids were preincubated in 5\% NGS in PBS with $0.05 \%$ Triton X-100 for 30 min up to $1 \mathrm{~h}$ at room temperature and incubated overnight in GluA1 or GluA2 antibody solutions at $4^{\circ} \mathrm{C}$. The grids were washed 6 times with drops of incubation solution for $5 \mathrm{~min}$ each, and then incubated in goat anti-rabbit IgG-conjugated to colloidal gold. After washing with incubation solution and PBS, specimens were postfixed in $2 \%$ glutaraldehyde in PBS for $15 \mathrm{~min}$, washed with distilled water, and contrasted according to standard procedures. Reacted ultrathin sections were analyzed with a JEOL JEM-1400 electron microscope.

Quantitative analysis of IEM. With NIH ImageJ 1.45 software, quantitative analysis of the distribution of immunogold particles for GluR1 or GluR2 along the postsynaptic membrane specialization was performed on 105-130 electron micrographs, which were acquired at the magnification of $58,000 \times$ from relevant groups, respectively. The image was acquired for every clearly defined synapse encountered, unlabeled or immunogold labeled, in random surveys of the target region. Some images had more than one synapse, so the number of synapses analyzed varied from 118 to 164 in different groups. A synapse was considered as immunopositive when it was associated with two or more immunoparticles (Zhou et al., 2011). The gold particles in the synaptic cleft, postsynaptic density (PSD), or at a maximum of $20 \mathrm{~nm}$ from the surrounding edge of the PSD were counted and defined as postsynaptic labeling (see Fig. 7A). Gold particles that were on the presynaptic membrane and outside the $20 \mathrm{~nm}$ surrounding edge of the PSD were not counted. Immunogold densities were presented as particles per linear micrometer of PSD or perisynaptic membrane. Immunogold labeling within $500 \mathrm{~nm}$ lateral to either side of the PSD along the plasma membrane were defined as perisynaptic labeling (see Fig. 7A) (Moga et al., 2006). The density of synapses per unit volume $\left(\mu \mathrm{m}^{3}\right)$ and PSD length were also estimated on five electron micrographs acquired at the magnification of $5000 \times$ for every grid (total three grids for each animal). The density of synapses per unit volume $\left(\mu \mathrm{m}^{3}\right)$ was calculated according to a previous report (Bi et al., 2010). For statistical analysis, these two indicators for each animal were reported as the average values of 15 electron micrographs, respectively. 
Statistical analysis. The data of CTA extinction were analyzed by repeated measures two-way ANOVA. Others were analyzed by two-tailed $t$ test or one-way ANOVA, which were followed by LSD post hoc test to compare means from several groups simultaneously. When equal variances were not assumed, a Dunnett's T3 test was used to compare the differences between groups. Significance was set at $p<0.05$. Results are expressed as mean \pm SEM. Data analyses were performed using SPSS statistical program, version 13.0.

\section{Results}

CTA consecutive extinction training but not acquisition enhances cofilin activity in the IrL

To study the role of ADF/cofilin in memory extinction, we observed changes in cofilin activity in the IrL during the extinction process. Previous studies and our data indicated that rats usually showed a substantial reduction of AIs during the CTA extinction, and the extent of AI decline from E3 to the fourth extinction trial (E4) was more than that from E1 to the second extinction trial (E2) $\left(F_{(5,54)}=10.987, p<0.001\right.$; one-way ANOVA) (Fig. $\left.1 A\right)$. If the cofilin is involved in CTA extinction, the activity of cofilin after E1 versus E3 might be different. To catch the changes of cofilin activity exactly between these two trials, we first examined the levels of $\mathrm{p}$-cofilin and total cofilin at various time points $(0$, 10, 30, 120, and $240 \mathrm{~min}$ ) after E1 using Western blot analysis (Fig. $1 B$ ). After normalizing the p-cofilin signals to the total cofilin levels, we observed that the rats exhibited a transient increase in cofilin phosphorylation at $30 \mathrm{~min}(p<0.001)$ and $120 \mathrm{~min}$ ( $p=0.001$, one-way ANOVA followed by post hoc test) (Fig. $1 C$ ) after E1, peaking at $30 \mathrm{~min}$ and returning to baseline at $240 \mathrm{~min}$. Therefore, the time point $30 \mathrm{~min}$ after extinction training was selected for measuring the phosphorylation levels of cofilin in the following experiments. Immunoblot analysis showed that the total cofilin levels in the IrL 30 min after E1 or E3 had no significant difference $(P=0.669$; two-tailed $t$ test $)$. However, the $\mathrm{p}$-cofilin levels were markedly reduced after E3 compared with E1 ( $p=$ 0.013 ; two-tailed $t$ test) (Fig. $1 D, E$ ), suggesting there was a gradual increase of cofilin activity during extinction. The cofilin activity change in the IrL during extinction was further confirmed by immunofluorescent staining for p-cofilin (Fig. $1 F$ ). Compared with the E1 group, the values of optical density for p-cofilin-positive cells in the IrL were significantly reduced after E3 ( $p=0.035$; two-tailed $t$ test) (Fig. $1 G$ ). These data suggested that the reduced aversive behavior during CTA extinction might be related to a temporal activation of cofilin in the IrL.

To test whether cofilin activity change in the IrL is specifically involved in CTA extinction, we examined the cofilin phosphorylation levels in the IrL during CTA acquisition. Thirty minutes after CTA conditioning, rats were killed and the IrL were collected and lysed. Different from extinction, we did not observe cofilin activity changes in the IrL during CTA acquisition $(p=$ 0.365). However, CTA acquisition induced significantly increased p-cofilin levels in the insular cortex (IC; $p=0.003$; two-tailed $t$ test) (Fig. $1 H, I)$. These results indicated the selective changes in cofilin activity during different memory process in different brain regions.

\section{LIMK1 and SSH1 coordinate to regulate cofilin activity during extinction}

Cofilin is mainly inactivated by phosphorylation of its Ser3 residue by LIMK1 and activated by dephosphorylation by SSH1, although alternative mechanisms do exist (Van Troys et al., 2008). To investigate the regulatory mechanism underlying the altered cofilin activity in the IrL during extinction, we examined
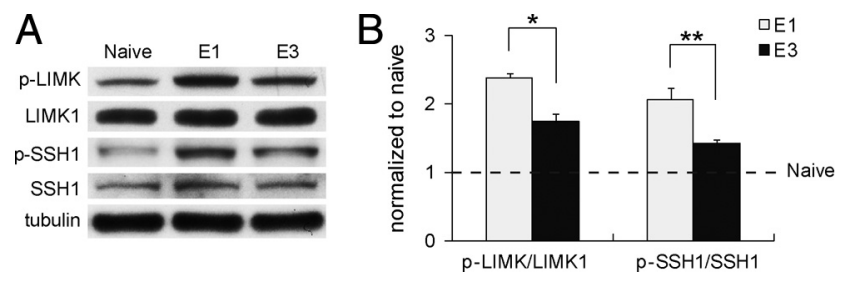

Figure 2. LIMK1 and SSH1 coordinate to regulate cofilin activity during extinction. $A, B$, Coregulation of cofilin activity by LIMK1 and SSH1 during CTA extinction. The same lysates as described in Figure $1 D$ were immunoblotted with antibodies against p-LIMK1 (Thr508), LIMK1, p-SSH1L (Ser978), and SSH1L. Representative immunoblots are shown in $A$, and the relative densitometric analysis is shown in $\boldsymbol{B}$. p-LIMK1/LIMK1 and p-SSH1/SSH1 ratio are normalized to naive group. $n=5$ rats. ${ }^{*} p<0.05,{ }^{* *} p<0.01$, versus E1 group. All values are presented as the mean \pm SEM.

A

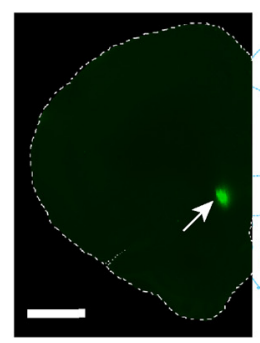

C
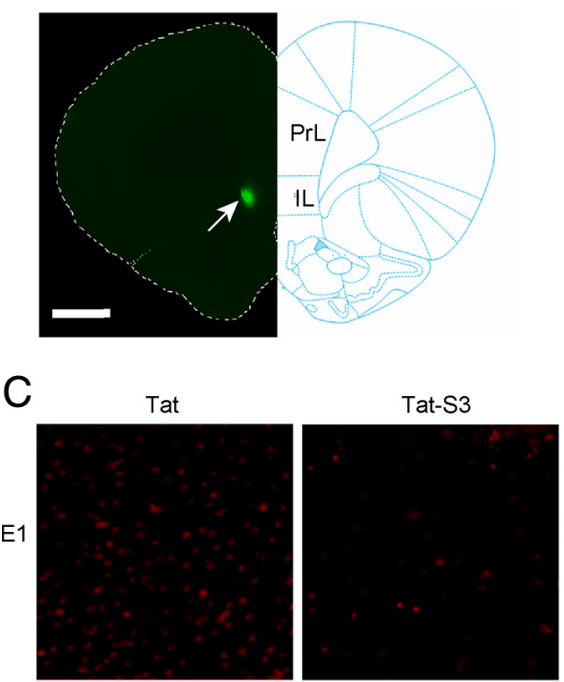

B

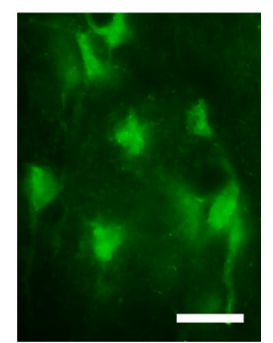

D

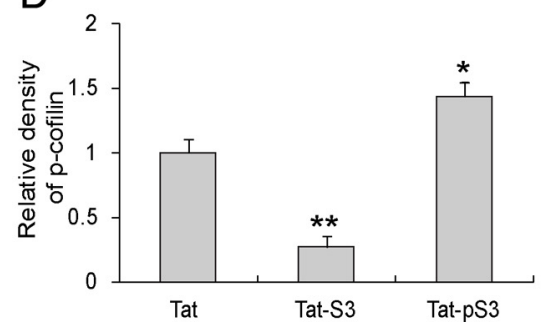

Figure 3. Microinjection of Tat, Tat-S3, or Tat-pS3 peptides into the IrL leads to cofilin activity alteration. Biotin-peptides were microinjected into the IIL ( $5 \mathrm{~nm}, 1 \mu$ l per side) immediately after E1. Thirty minutes after injection, the rats were perfused, then the brains were removed, sliced, and subjected to streptavidin-conjugated Alexa Fluor 488 (green) $(\boldsymbol{A}, \boldsymbol{B})$ or p-cofilin antibody staining $(\boldsymbol{C})$. $\boldsymbol{A}$, Representative image showed the location and diffusion range of Tat-S3 after microinjection. Scale bar, $1 \mathrm{~mm}$. B , High magnification of Tat-S3-labeled cells showed equal distribution of peptides in soma and dendrites. Scale bar, $20 \mu \mathrm{m}$. C, Representative images of immunofluorescence-stained p-cofilin in the IrL from Tat, Tat-S3, or Tat-pS3 peptide-injected groups respectively. Scale bar, $50 \mu \mathrm{m}$. D, Relative quantification of density of p-cofilin after immunofluorescent staining. p-cofilin levels were significantly decreased after Tat-S3 injection and increased after Tat-pS3 injection compared with Tat-injected group. $n=3$ rats. ${ }^{*} p<0.05,{ }^{* *} p<0.01$ versus Tat-control group. All values are presented as the mean \pm SEM.

the activity of LIMK1 and SSH1 during the process of memory extinction. The IrL samples were dissected $30 \mathrm{~min}$ after E1 and E3, with naive rats as control. Because LIMK1 is activated by its Thr508 phosphorylation and SSH1 is inactivated by its Ser978 
A

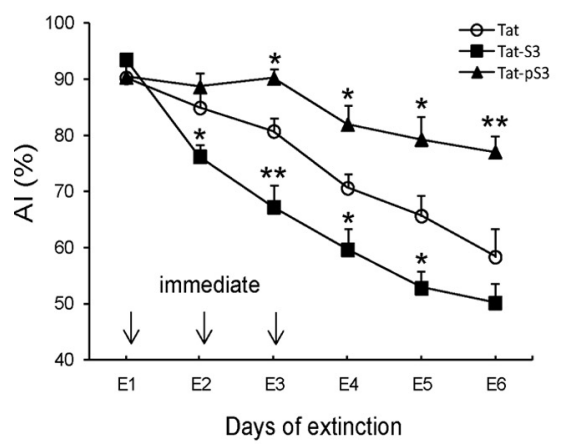

B

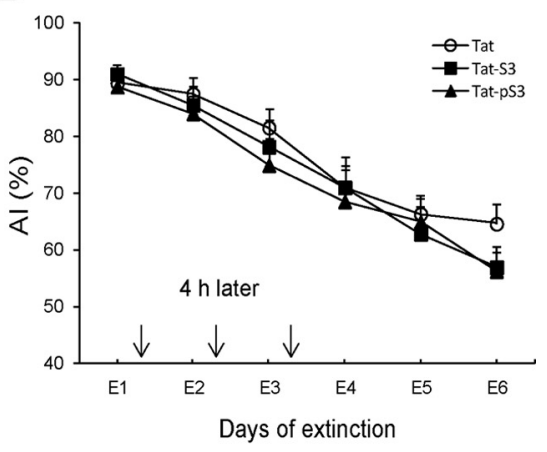

(data not shown). Figure $3 A$ showed the representative picture of Tat-S3 peptide in the IrL at $30 \mathrm{~min}$ after microinjection. The peptide diffused only in the IrL and could be detected in both cell body and dendrites (Fig. 3B), which suggested that the peptide successfully entered into the IrL cells. The effects of the peptides on cofilin activity were further examined by immunofluorescent staining with $\mathrm{p}$-cofilin antibody. Compared with Tat-injected control group, Tat-S3 or Tat-pS3 peptide injection could decrease or increase the optical density values of p-cofilin in the IrL after E1, respectively $\left(F_{(2,6)}=30.76, p=\right.$ 0.001; one-way ANOVA) (Fig. $3 C, D$ ), which indicated that Tat-S3 or Tat-pS3 could be served as cofilin activator or inhibitor, respectively.

To investigate the role of cofilin during memory extinction, Tat, Tat-S3, or TatpS3 peptides were bilaterally infused into the IrL immediately after the exposure to E1-E3. Compared with the Tat-control, Tat-S3 microinfusion significantly facilitated memory extinction, whereas Tat-pS3 had the opposite effect (group, $F_{(2,135)}=97.36, p<$ 0.001 ; extinction trial, $F_{(5,135)}=37.055$, $p<0.001$; interaction, $F_{(10,135)}=3.555, p=$ 0.002 ; repeated measures two-way ANOVA) (Fig. 4A), suggesting that the change of cofilin activity in the IrL could regulate the extinction of aversive memory. In addition, we observed that administra-

Figure 4. Inhibition or enhancement of cofilin activity impairs or facilitates memory extinction respectively. $\boldsymbol{A}$, Rats were subjected to CTA extinction procedure, and Tat, Tat-S3, or Tat-pS3 was microinfused into the IrL immediately after E1-E3. $n=10$ rats. $\boldsymbol{B}$, Rats were subjected to CTA extinction procedure and Tat, Tat-S3, or Tat-pS3 was microinfused into the IrL $4 \mathrm{~h}$ after E1-E3. $n=9$ rats. $C$, Rats were subjected to contextual fear extinction procedure and Tat, Tat-S3, or Tat-pS3 was microinfused into the IrL immediately afterE1-E2. $n=$ $8-9$ rats. ${ }^{*} p<0.05,{ }^{* *} p<0.01$ versus Tat-control group. All values are presented as the mean \pm SEM.

phosphorylation, we used specific antibodies to determine the activity changes of LIMK1 and SSH1. Notably, we observed that extinction training decreased LIMK1 activity $(p=0.032)$, whereas increased SSH1 activity ( $p=0.006$; two-tailed $t$ test; Fig. $2 A, B)$ when their phosphorylation levels were compared between E1 and E3, suggesting that the synergistic effects of LIMK1 and SSH1 increased cofilin activity during memory extinction processes.

\section{Cofilin activity is required for CTA extinction}

The above results showed the altered cofilin activity in the IrL during CTA extinction; however, whether this change is functionally necessary for CTA extinction is still unknown. We next investigated the effect of temporally manipulating cofilin activity in the IrL on CTA extinction. To this end, we used two synthetic peptides to alter cofilin activity according to the previous report (Aizawa et al., 2001). The S3-peptide containing the unique phosphorylation site of cofilin was used as a competitive inhibitor for LIMKs and served as a cofilin activator. Conversely, the pS3-peptide, derived from 1 to 16 residues of cofilin with Ser3 phosphorylation, was designed to act as an inhibitor of SSH1 and served as a cofilin inhibitor. These peptides were fused with a Tat-like sequence that allowed the peptide to penetrate into cells (Toda et al., 2006) and a biotin molecule that could be detected. After infusion of these peptides into the IrL, respectively, rats were perfused with $4 \%$ paraformaldehyde at $30 \mathrm{~min}, 2 \mathrm{~h}$, or $4 \mathrm{~h}$ to detect the location and diffusion of these peptides. The peptides were detectable at maximum level at $30 \mathrm{~min}$, detectable at intermediate level at $2 \mathrm{~h}$, and no longer detectable at $4 \mathrm{~h}$ after infusion tion of Tat-S3 or Tat-pS3 peptide into the IrL $4 \mathrm{~h}$ after E1-E3 had no effect on memory extinction (group, $F_{(2,120)}=1.731, p=0.198$; extinction trial, $F_{(5,120)}=29.975, p<0.001$; interaction, $F_{(10,120)}=$ $0.27, p=0.963$; repeated measures two-way ANOVA) (Fig. $4 B$ ), suggesting the cofilin activity regulates extinction within a limited interval after exposure to the extinction trial.

To test whether cofilin activity in the IrL plays a general role in memory extinction, contextual fear extinction was further used. Consistent with the results obtained from CTA extinction, Tat-S3 microinfusion significantly facilitated contextual fear memory extinction in the next 2 extinction days, whereas Tat-pS3 microinfusion impeded the extinction of contextual memory (E2, $F_{(2,22)}=13.9, p<0.001 ; \mathrm{E} 3, F_{(2,22)}=14.542, p<0.001$; one-way ANOVA) (Fig. 4C). The locomotor activities of the rats were not influenced upon peptide treatment (data not shown). Together, these results suggested that cofilin activity in the IrL may play a general role in memory extinction.

\section{Memory extinction facilitates GluA1 and GluA2 synaptic trafficking in the IrL}

Glutamate receptors are the principle mediators of excitatory synaptic transmission and are essential for the expression of various forms of synaptic plasticity including LTP, widely studied cellular models for learning and memory (Yao et al., 2008; Zhou et al., 2011). Whether cofilin activity alteration regulates CTA extinction through glutamate receptors is still unknown. We first investigated whether the glutamate receptors trafficking to synapse were altered in the IrL during extinction. We isolated crude particulate fraction of the synapse termed SNS from the IrL 30 
min after E1 and E3. SNS is suggested for entities in which a presynaptic sac (synaptosome) is attached to a resealed postsynaptic sac (neurosome) (Hollingsworth et al., 1985; Villasana et al., 2006). All subunits of AMPARs and the NR1 subunit of the NMDA receptor were detected by immunoblotting (Fig. 5A-E). The levels of GluA1 and GluA2 in the SNS fraction were notably higher after E3 compared with E1 (GluA1, $p=0.006$; GluA2, $p=$ 0.007), whereas the levels of GluA3, GluA4, and NR1 were not significantly changed (GluA3, $p=0.083$; GluA4, $p=$ 0.823; NR1, $p=0.149$; two-tailed $t$ test) (Fig. $5 F$ ). In a crude homogenized IrL fraction, the expression levels of GluA1 and GluA2 were unchanged (GluA1, $p=$ 0.878 ; GluA2, $p=0.671$; two-tailed $t$ test) (Fig. 5H-J), which suggested that the extinction induced increases in synaptic GluA1 and GluA2 levels were not due to the global increase in their expression but rather a translocation from extrasynaptic region to synapses. It suggests that the surface AMPARs are the essential and functional receptors during synaptic plasticity (Kullmann, 2003). Thus, we measured the surface levels of the glutamate receptors in the SNS fraction by surface biotinylation assay. We labeled surface membrane-associated proteins from the SNS fraction by biotinylation and subsequently precipitated with a neutravidin-agarose conjugate. When normalized to the protein levels in SNS, we observed an increase in the surface levels of the GluA1 and GluA2 subunits but not other subunits $30 \mathrm{~min}$ after E3 compared with E1 (GluA1, $p=0.002$; GluA2, $p=0.004 ;$ GluA3, $p=0.973$; GluA4, $p=$ 0.564 ; NR1, $p=0.75$; two-tailed $t$ test) (Fig. 5G). These results suggested that CTA memory extinction not only induced the translocation of GluA1 and GluA2 into synapses but also facilitated their synaptic surface membrane recruitment in the IrL. Interestingly, the effect was specific to GluA1 and GluA2 subunits, as other subunits of glutamate receptors remained unchanged.

\section{Cofilin activity regulates GluA1 and GluA2 synaptic trafficking during memory extinction}

Although the above data showed GluA1 and GluA2 synaptic trafficking in the IrL during CTA extinction, it is still unclear whether these changes are related with cofilin activity. To address this question, peptides Tat-S3 and Tat-pS3 were used to enhance or inhibit cofilin activity, respectively. Immediately after the exposure to E1-E3, rats were injected with either Tat-control peptide or the functional peptides. Thirty minutes after E3, rats were killed. The IrL was dissected to isolate SNS and surface membrane-associated proteins were precipitated as previously described and analyzed by immunoblotting. Consistent with our

C

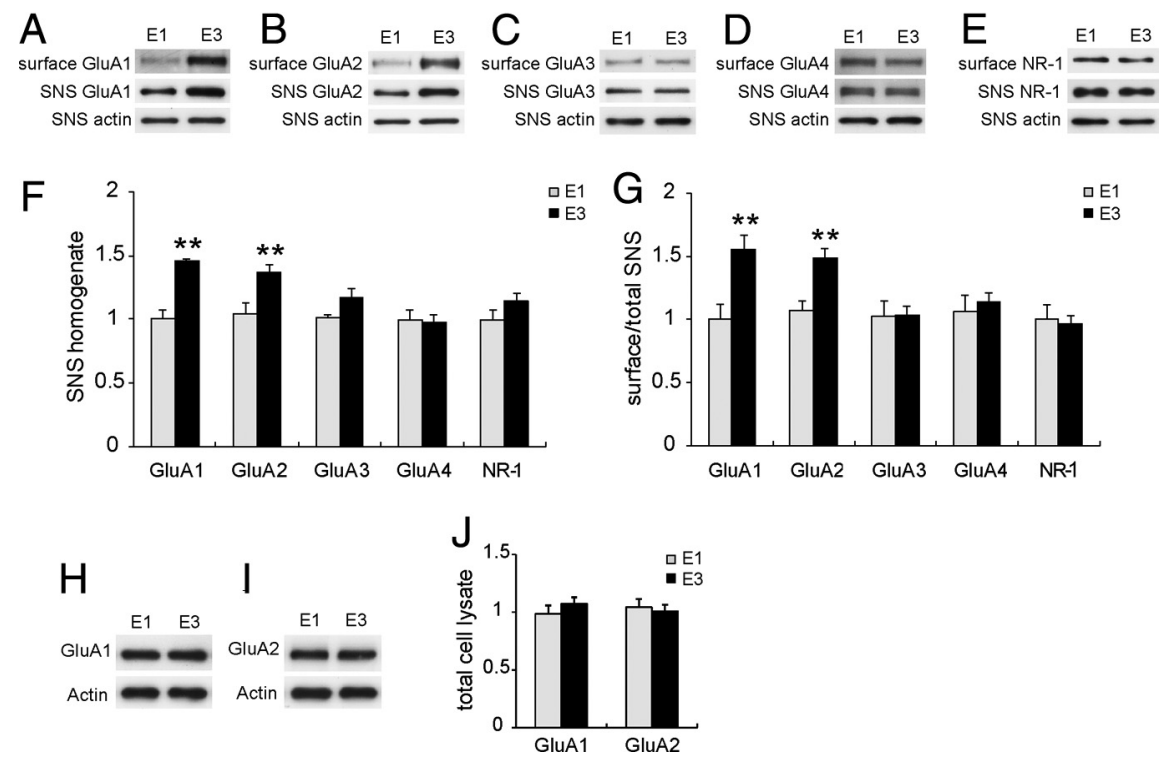

Figure 5. Memory extinction facilitates GluA1 and GluA2 synaptic translocation and membrane recruitment in the IrL. $\boldsymbol{A}-\boldsymbol{E}$, Representative immunoblots of GluA1, GluA2, GluA3, GluA4, and NR1 receptors in synaptic membranes and SNS. The IrL were 列 30 min after E1 or E3. F, Relative quantification of GluA1, GluA2, GluA3, GluA4, and NR1 receptors in synaptoneurosomes Representative immunoblot and densitometric analysis of total GluA1 and GluA2 in the IrL protein extracts 30 min after E1 and E3.
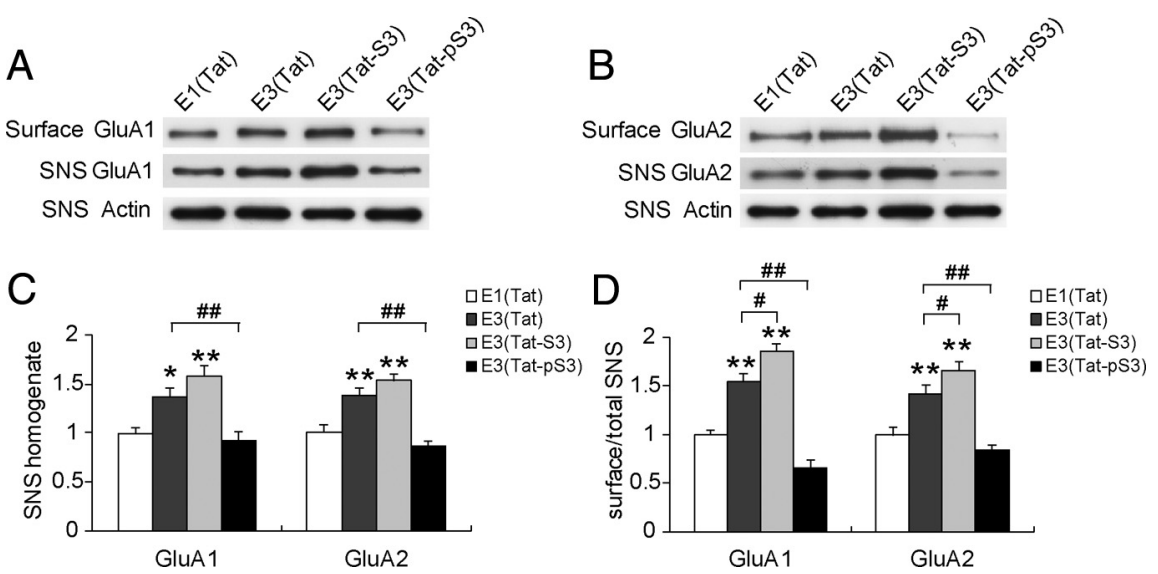

Figure 6. Cofilin activity regulates GluA1 and GluA2 synaptic translocation and membrane recruitment during memory extinction. $\boldsymbol{A}, \boldsymbol{B}$, Representative immunoblots of GluA1 and GluA2 subunits in total SNS and SNS surface in the IrL extracts from different $6-10$ rats. $D$, Relative quantification of surface/total GluA1 and GluA2 in SNS. $n=6-10$ rats. ${ }^{*} p<0.05,{ }^{* *} p<0.01$ versus E1 (Tat) group. ${ }^{\#} p<0.05,{ }^{\# \#} p<0.01$, versus E3 (Tat) group. All values are presented as the mean \pm SEM.

previous data, after E3, the Tat-control group had significantly increased levels of GluA1 and GluA2 in SNS and synaptic membrane compared with E1 [SNS (GluA1), $p=0.019$; SNS (GluA2), $p=0.008$; surface (GluA1), $p<0.001$; surface (GluA2), $p<$ 0.001 ; one-way ANOVA followed by post hoc test] (Figure $6 A-D$ ). These results further confirmed that extinction training could facilitate the GluA1 and GluA2 synaptic translocation and synaptic membrane recruitment. Compared with the E3 (Tat) group, peptide Tat-S3 infusion significantly increased the surface levels of GluA1 and GluA2 [SNS (GluA1), $p=0.227$; SNS (GluA2), $p=0.223$; surface (GluA1), $p=0.014$; surface (GluA2), $p=0.018$; one-way ANOVA followed by post hoc test] (Figure $6 A-D$ ). On the contrary, Tat-pS3 injection decreased not only synaptic but also postsynaptic surface levels of GluA1 and GluA2 compared with E3 (Tat) group 
A

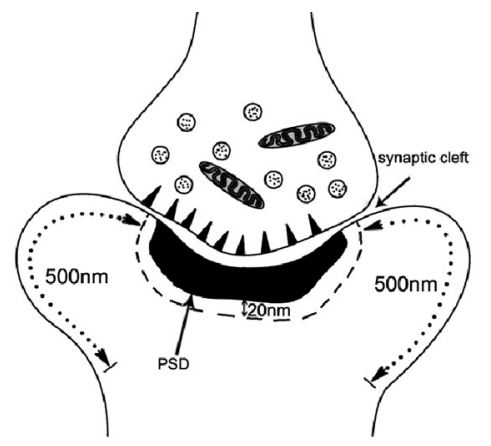

GluA1

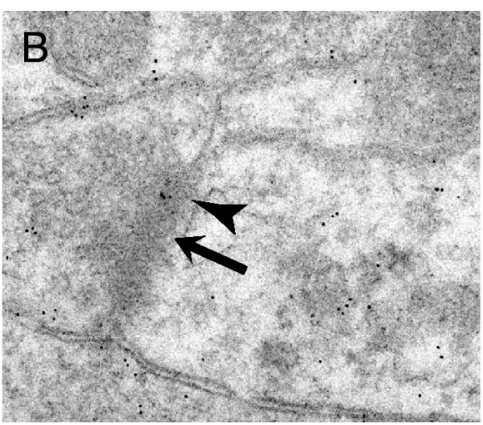

E1

(Tat)

E3

(Tat)

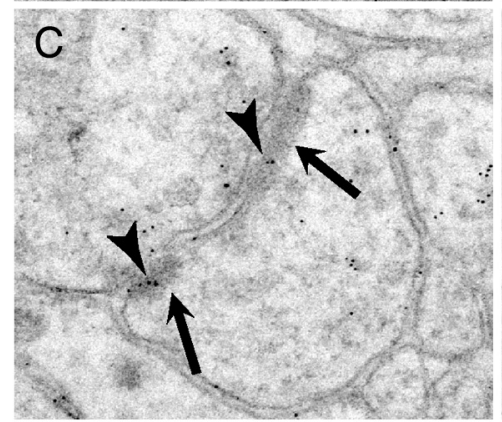

E3

(Tat-S3)

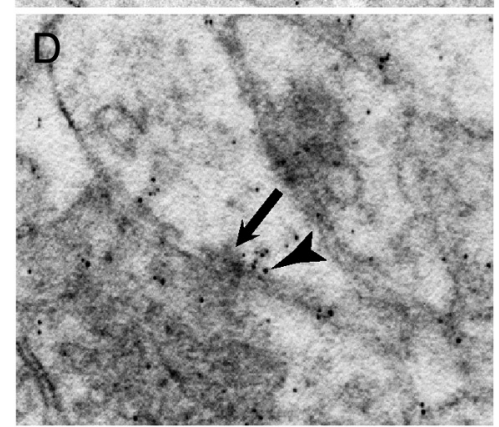

E3

(Tat-pS3)

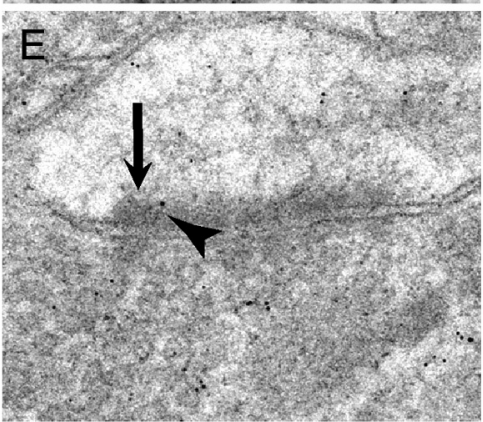

GluA2
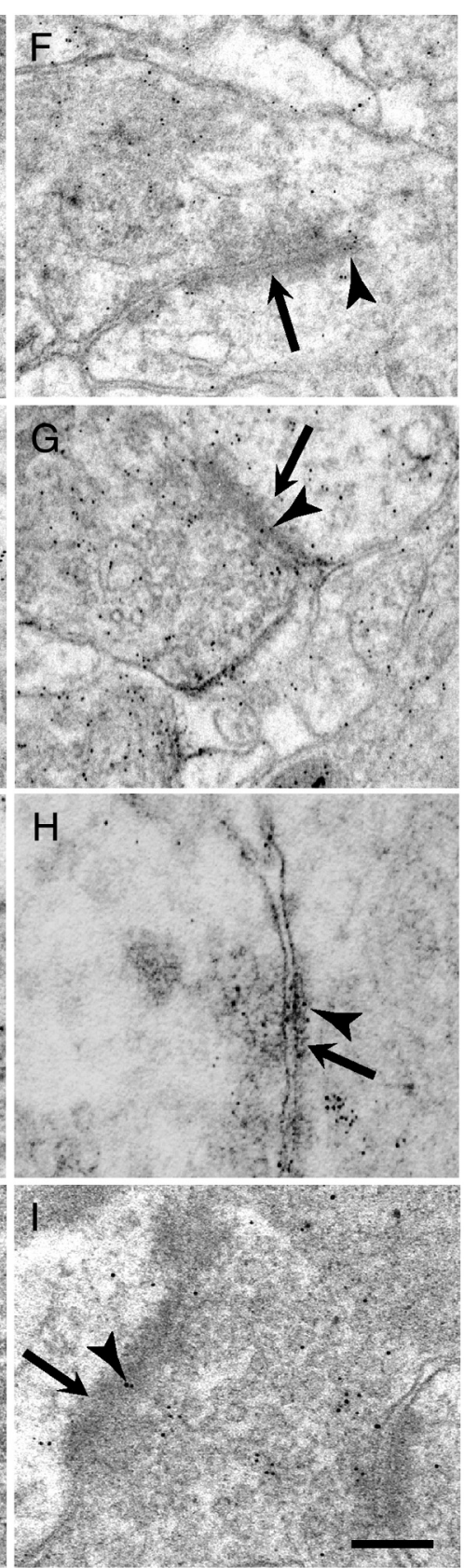
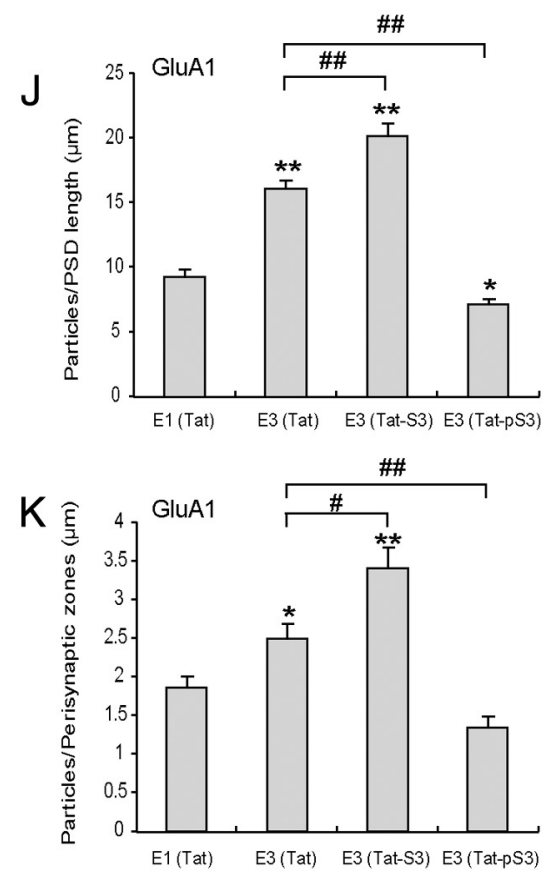

$\mathrm{L}$

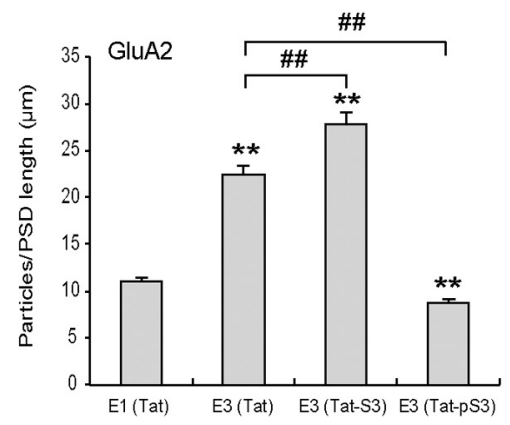

M

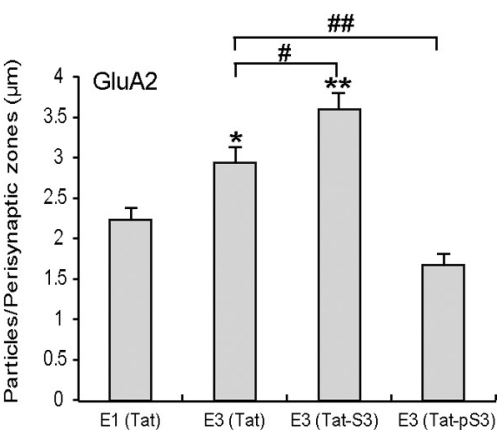

Figure 7. Cofilin activity regulates the levels of GluA1 and GluA2 subunit on postsynaptic membrane in the IrL. A, Diagram for how to calculate immunogold particles in PSD of a synapse. Immunogold particles that located in synaptic cleft area, PSD, or a $20 \mathrm{~nm}$ boundary region surrounding the edges of the PSD were all counted as the PSD particles. (Figure legend continues.) 
[SNS (GluA1), $p<0.001$; SNS (GluA2), $p<$ 0.001 ; surface (GluA1), $p<0.001$; surface (GluA2), $p<0.001$; one-way ANOVA followed by post hoc test] (Figure 6A-D). These data suggested that the memory extinction induced AMPARs synaptic trafficking in the IrL were dependent on the cofilin activity.

To directly observe the changes in GluA1 and GluA2 levels at synapses, electron microscopy postembedding immunogold labeling method was further used to examine the GluA1 and GluA2 synaptic location during memory extinction. The results showed that GluA1immunogold or GluA2-immunogold particles were concentrated in the synaptic region, locating at plasma membrane or intracellular (Fig. 7A-I). In Tat control group, the percentage of GluA1 or GluA2 labeled synapses was significantly increased in E3 compared with E1 [E1 (Tat), GluA1:59.7\%, $n=159$; E3 (Tat), GluA1: $82.1 \%, n=123 ; \chi^{2}=16.366, p<0.001$; E1 (Tat), GluA2: $69.5 \%, n=141$; E3 (Tat), GluA2: $89.0 \%, n=118 ; \chi^{2}=$ $14.384, p<0.001 ; \chi^{2}$ test]. Moreover, the immunogold densities of GluA1 or GluA2 in the PSD (both $p<0.001$ ) (Fig. $7 \mathrm{~J}, L$ ) and in the perisynaptic zone (GluAl, $p=$ 0.016; GluA2, $p=0.012$; one-way ANOVA followed by post hoc test) (Fig. $7 \mathrm{~K}, \mathrm{M}$ ) were significantly increased in E3 (Tat) group compared with E1 (Tat) group. Upon the Tat-S3 treatment, the immunogold densities of GluA1 or GluA2 in the PSD (both $p<0.001$ ) (Fig. $7 J, L$ ) and in the perisynaptic zone (GluA1, $p=$ 0.032; GluA2, $p=0.019$ ) (Fig. $7 K, M$ ) were significantly increased compared with E3 (Tat) group. Conversely, Tat-pS3 treatment could not only block the extinction induced increase in the percentage of GluA1 or GluA2 labeled synapses [E3 (TatpS3), GluA1: $54.9 \%, n=164 ; \chi^{2}=23.421, p<0.001$; E3 (TatpS3), GluA2: $\left.63.8 \%, n=138 ; \chi^{2}=21.798, p<0.001\right]$, but also significantly decrease the immunogolds densities of GluA1 or GluA2 in the PSD and perisynaptic zone (all $p<0.001$, one-way ANOVA followed by post hoc test) (Fig. 7J-M). Together, these results further demonstrated that extinction could induce GluA1 and GluA2-containing AMPAR recruitment to the postsynaptic membranes, which was regulated by cofilin activity.

(Figure legend continued.) Particles were considered perisynaptic if clearly located on the membrane within $500 \mathrm{~nm}$ the PSD. $\boldsymbol{B}-\boldsymbol{E}$, Representative images of GluA1-labeled synapses in the IrL from E1 $(\boldsymbol{B})$, E3 rats with Tat treatment $(\boldsymbol{C})$, Tat-S3 treatment $(\boldsymbol{D})$ or Tat-pS3 treatment (E). $\boldsymbol{F}$-I, Representative images of GluA2-labeled synapses in the IrL from E1 (Tat) (F), E3 rats with Tat $(\boldsymbol{G})$, Tat-S3 treatment $(\boldsymbol{H})$, or Tat-pS3 treatment $(\boldsymbol{I})$. The arrows indicate where the PSD is located; the arrowheads indicate $6 \mathrm{~nm}$ gold particles. Scale bar, $0.2 \mu \mathrm{m}$. J, $\boldsymbol{K}$, The number of GluA1 gold particles per micrometer PSD $(\boldsymbol{J})$ and per micrometer of perisynaptic zone $(\boldsymbol{K})$ after E1 or E3 with different peptide treatment. $L, M$, The number of GluA2 gold particles per micrometer PSD $(\boldsymbol{L})$ and per micrometer of perisynaptic zone $(\boldsymbol{M})$ after E1 or E3 with different peptide treatment. $n=88-119$ synapses from 3 rats. ${ }^{*} p<0.05,{ }^{* *} p<0.01$, versus E1 (Tat) group. ${ }^{\#} p<0.05,{ }^{\# \#} p<0.01$, versus E3 (Tat) group. All values are presented as the mean \pm SEM.

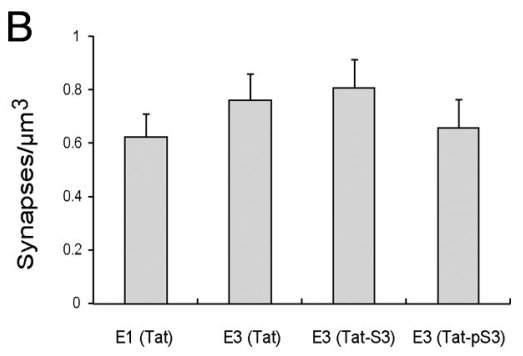

D
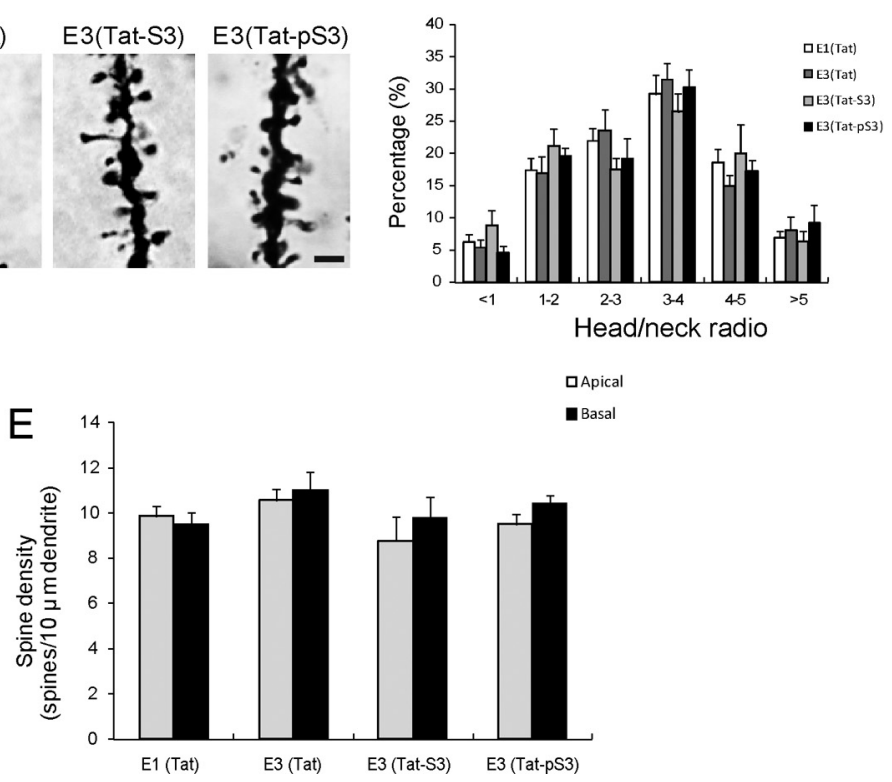

Figure 8. Cofilin activity does not change the synaptic structure in the IrL after E3. $A, B$, Quantitative analysis of PSD length $(\boldsymbol{A})$ and synapse density $(\boldsymbol{B})$ from the IrL electron micrographs after E1 or E3 with different peptide treatment. $n=3$ rats. $C$, Repreve images of Golgi staining from the indicated groups. Scale bar, $2 \mu \mathrm{m}$. D, Distribution of head/neck ratios of randomly ical or basal dendritic spines in the IrL. Dendritic spine density represents the average number of spines per $10 \mu \mathrm{m}$ dendritic length. $n=5$ rats. All values are presented as the mean \pm SEM.

Interestingly, neither the three consecutive extinction trainings nor the additional regulation of cofilin activity by Tat-S3 or Tat-pS3 microinfusion could change the PSD length and the synaptic density (PSD length, $F_{(3,8)}=2.129, p=0.175$; synaptic density, $F_{(3,8)}=0.708, p=0.574$; one-way ANOVA) (Fig. $8 A, B$ ) These results suggested that extinction induced AMPARs synaptic trafficking might not be directly associated with synaptic structural remodeling. Meanwhile, Golgi staining was performed to observe the structure changes of spines (Fig. 8C). There were no significant changes in the ratios of the spine's head to neck, and the spine density in apical or basal dendrites among these groups (all $p>0.05$; one-way ANOVA) (Fig. 8D,E). These results indicate that postsynaptic AMPARs trafficking and spine structure are differentially regulated during memory extinction.

\section{AMPARs synaptic trafficking mediate the effect of cofilin activity on memory extinction}

We observed that memory extinction could induce temporal increased cofilin activity and the recruitment of GluA1 and GluA2 into postsynaptic membranes, so we sought to investigate whether the role of cofilin activity in extinction was mediated by AMPAR trafficking indeed. A pep-R845A peptide conjugated to Tat, which mimics the NSF binding site in GluA2 to interfere the interaction between NSF and GluA2, was used to decrease the 
A

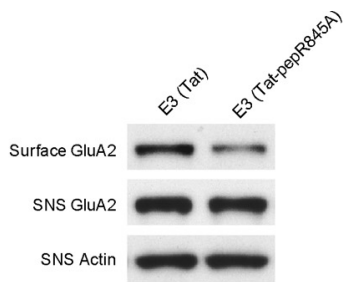

$\mathrm{B}$
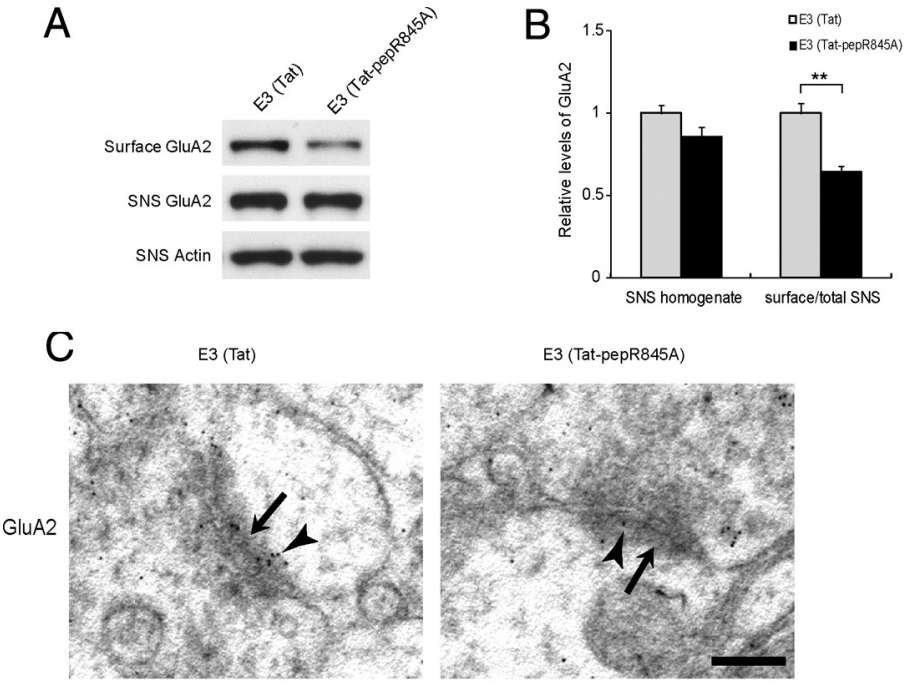

D

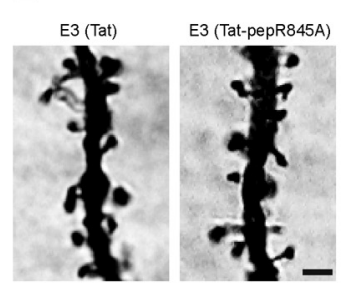

E
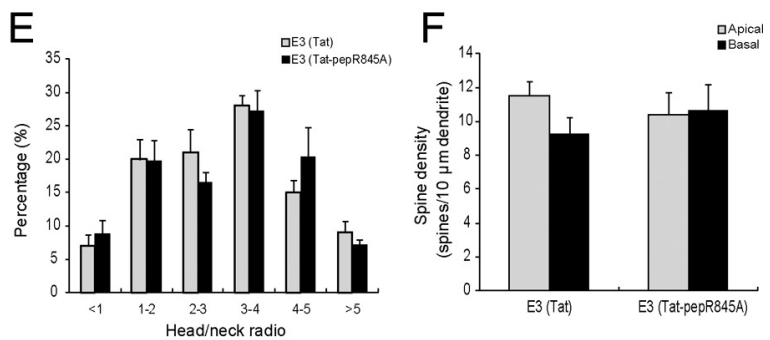

G

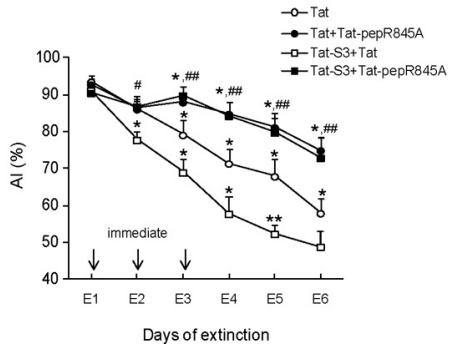

$\mathrm{H}$

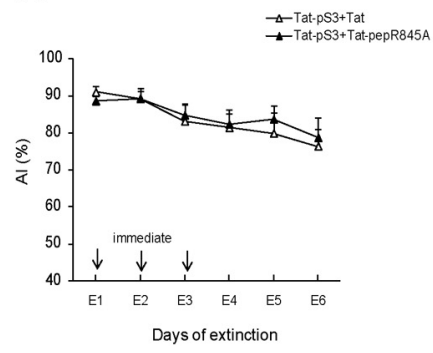

Figure 9. GluA2-containing AMPA synaptic membrane recruitment mediated the effect of cofilin on memory extinction. $A$, Representative immunoblots of GluA2 receptors in synaptic membranes and SNS after Tat or Tat-pepR845A treatment for three consecutive extinction trials. $\boldsymbol{B}$, Relative levels of GluA2 in SNS and surface/total SNS. E3 (Tat) control is indicated at 1. $n=6-7$ rats. C, Representative images of GluA2-labeled synapses in the IrL after Tat or Tat-pepR845A treatment for three consecutive extinction trials. The arrows indicate where the PSD is located; the arrowheads indicate $6 \mathrm{~nm}$ gold particles. Scale bar, $0.2 \mu \mathrm{m}$. $\boldsymbol{D}$, Representative images of Golgi staining in the IrL after Tat or Tat-pepR845A treatment for 3 consecutive days. Scale bar, $2 \mu \mathrm{m}$. $\boldsymbol{E}$, Distribution of head/neck ratios of randomly selected spines from apical dendrites of layer II/III pyramidal neurons in the IrL. $n=$ 5 rats. $\boldsymbol{F}$, Quantification of linear density of apical or basal dendritic spines in the IrL. $n=5$ rats. All samples above were collected at 30 min after $\mathrm{E} 3$ with different peptide treatment. $\mathbf{G}, \boldsymbol{H}$, Rats were subjected to CTA extinction procedure and injected with respective peptides immediately after E1-E3. $n=8-10$ rats. ${ }^{*} p<0.05,{ }^{* *} p<0.01$ versus Tat group, ${ }^{\#} p<0.05,{ }^{\# \#} p<0.01$ versus Tat-S3+Tat group. All values are presented as the mean \pm SEM.

GluA2-containing AMPA receptor's synaptic membrane recruitment (Joels and Lamprecht, 2010; Anggono and Huganir, 2012). First, to better interpret the effect of the pepR845A microinfusion on GluA2-containing AMPA synaptic and synaptic surface recruitment during memory extinction, immunoblotting, immunogold labeling, and Golgi staining were used, respectively. Immediately after E1-E3, rats were injected with Tat or TatpepR845A. Thirty minutes after E3, rats were decapitated and the IrL was dissected. Immunoblotting results showed that Tat-pepR845A administration could decrease the surface levels but not the SNS fraction of GluA2 (surface, $p<0.001$; SNS, $p=0.096$; two-tailed $t$ test) (Fig. 9B). Moreover, both the immunogold densities of GluA2 in the PSD and in the perisynaptic zone were decreased significantly $(p<0.001$ and $P=0.022$; two-tailed $t$ test $)$ (Fig. 9C). However, we did not find TatpepR845A microinfusion has any effect on the morphology and quantity of synapses in the IrL, which was indicated by no significant difference in the PSD length $(p=0.39)$, synaptic density $(p=0.602)$, ratios of spine's head to neck (all $p>0.05$ ) and the spine density in apical or basal dendrites (both $p>0.05$, two-tailed $t$ test) (Fig. $9 D-F$ ) between the Tat-pepR845A-treated and Tat-control group. These results suggested that Tat-pepR845A treatment could effectively block GluA2 synaptic surface recruitment during CTA extinction.

Then we combined the microinfusion of Tat-pepR845A, Tat-S3, and Tat-pS3 to observe the effect on CTA extinction. We found injection of Tat-pepR845A into the IrL could significantly block memory extinction when compared with Tat control group (group, $F_{(1,107)}=25.838, p<0.001$; extinction trials, $F_{(5,107)}=17.298, p<$ 0.001 ; interaction, $F_{(5,107)}=2.629, p=0.03$; repeated measures two-way ANOVA) (Fig. $9 G)$, suggesting that GluA2-dependent AMPARs synaptic trafficking in the IrL was involved in CTA extinction. Importantly, we found Tat-pepR845A infusion totally blocked the extinction facilitating effect of Tat-S3 (group, $F_{(1,113)}=88.633$, $p<0.001$; extinction trials, $F_{(5,113)}=$ 22.672, $p<0.001$; interaction, $F_{(5,113)}=$ 5.841, $p<0.001$; repeated measures two-way ANOVA) (Fig. 9G), which suggested that GluA2 synaptic trafficking acted downstream of cofilin to mediate memory extinction. Moreover, combined administration of Tat-pS3 and TatpepR845A could not further delay memory extinction (group, $F_{(1,101)}=0.162, p=$ 0.693; extinction trials, $F_{(5,101)}=3.08$, $p=0.014$; interaction, $F_{(5,101)}=0.154$, $p=0.978$; repeated measures two-way ANOVA) (Fig. 9H). These results suggested that AMPARs synaptic trafficking and cofilin activity were in the same pathway to regulate memory extinction and AMPAR synaptic trafficking mediated the effect of cofilin on memory extinction.

\section{Discussion}

Actin dynamics provide an important mechanism for the regulation of synaptic function and structure. Cofilin regulates actin dynamics through their filament-severing activity (Bernstein and Bamburg, 2010). In this study, we observed temporally decreased phosphorylation of cofilin in the IrL during CTA extinction. Pharmacological elevation of cofilin activity in the IrL facilitates, whereas inhibition of cofilin activity blocks, memory extinction. Using synaptoneurosome biotinylation and electron microscopy immunogold labeling assay, we found that increased cofilin activity associated with memory extinction was essential for the AMPAR translocation to synapse and recruitment to postsynaptic membrane. Moreover, 
we demonstrated that the role of cofilin activation in the memory extinction process depends on AMPAR postsynaptic membrane recruitment. Finally, we showed that cofilin plays distinct roles in modification of synaptic function and spine morphology.

Our results provide several new insights into the role of cofilin in memory extinction. First, we found increased cofilin activity in the IrL during memory extinction but not memory acquisition, and manipulating cofilin activity could alter memory extinction process. Memory extinction is a new form of learning and the IrL has been shown to play an important role in the extinction of conditioned emotional response (Milad and Quirk, 2002; Barrett et al., 2003; Miller, 2004). Cofilin has actin severing and depolymerizing activity, which is required for the reorganization of actin filaments. We observed a significantly decreased phosphorylation of cofilin after E3, indicating that extinction leads to increased cofilin activity. Previous reports showed that LIMKs evolved the specific task of phosphorylating cofilin and SSH was a dedicated cofilin phosphatase at the critical Ser3 residue. Therefore, we investigate the role of LIMK and SSH during extinction. We found that extinction led to decreased phosphorylation of LIMK1 and SSH1 after E3 without affecting the total amount of LIMK1 and SSH1 proteins, suggesting a reduction in LIMK activity, whereas an elevation in SSH activity. Thus, the altered activity of LIMKs and SSH during extinction could act coordinately to activate cofilin. Notably, we found that microinfusion of Tat-S3 into the IrL, which enhances cofilin activity, could facilitate extinction whereas inhibition of cofilin activity by infusion of Tat-pS3 impaired extinction, which demonstrated the functional importance of cofilin activity in extinction. Many mental disorders, such as posttraumatic stress disorder (PTSD), are conditions characterized by increased anxiety, as well as a reduced ability to memory extinction (Myers and Davis, 2002; Davis et al., 2006). The promotion of the extinction processes may help to treat such disorders, which are defined as the reduction of an aversively motivated behavior (Davis et al., 2006). Our study indicates that cofilin could be a promising drug target for emotional disorders.

Second, we found the temporal elevation of cofilin activity during extinction enhances GluA1 and GluA2, but not NR1, translocation to synapse and moreover their recruitment into postsynaptic membrane, which could facilitate memory extinction. The actin cortex is known to present a physical barrier for vesicle fusion with the plasma membrane (Aunis and Bader, 1988; Eitzen, 2003). Thus, cofilin-regulated actin dynamics may be required for vesicular delivery of AMPARs to the surface. A previous in vitro study using live imaging found that a transient activation of ADF/cofilin by dephosphorylation during chemically induced LTP potentiates GluA1 trafficking to the postsynaptic surface (Gu et al., 2010). Notably, they found that either the actin depolymerizing drug latrunculin $\mathrm{A}$ or the stabilization of actin filaments by jasplakinolide could block cLTP-induced AMPAR insertion, suggesting actin dynamics are required in AMPAR trafficking. Lateral diffusion of a single GluA2 receptor was also found to be slowed down in cofilin knock-out neurons (Rust et al., 2010). However, these studies were performed in cultured hippocampal neurons, and whether cofilin activity involved in AMPAR trafficking in vivo remains unclear. We found that increased cofilin activity during extinction could not only increase the translocation of AMPARs to synapses but also potently drive synapse-localized AMPAR recruitment into postsynaptic membranes. Temporal increasing cofilin activity facilitates, whereas inhibition of cofilin activity blocks, GluA1 and GluA2 postsynaptic membrane recruitment, which further suggests that cofilin activity is required for AMPAR mobility during memory extinction. The efficient recruitment of AMPARs to postsynaptic membrane might present a mechanism for rapid enhancement of synaptic strength. We found that extinction induced AMPAR synaptic trafficking was specific to GluA1 and GluA2, but not GluA3, GluA4, or NR1. The detailed mechanisms underlying the selective effect of cofilin-mediated actin dynamics on receptor trafficking need to be further investigated.

Third, we found that blocking GluA2 postsynaptic membrane recruitment abolished the effect of cofilin activity on memory extinction, which indicated that AMPAR synaptic trafficking mediated the action of cofilin on memory extinction. A previous study reported that intra-IrL injection of a potentiator of AMPARs, 4-[2(phenylsulfonylamino) ethylthio]-2,6-difluorophenoxyacetamide (PEPA), facilitates extinction learning for contextual fear memory (Zushida et al., 2007). Together with our study, it is suggested that manipulating AMPAR synaptic trafficking or function in the $\operatorname{IrL}$ could regulate extinction learning.

Finally, our data indicate that AMPAR trafficking to PSD during memory extinction was not directly coupled to a change in PSD length and synapse density. Synapse AMPAR addition and spine enlargement appeared to be temporally separated in extinction learning. In hippocampal CA3-CA1 synapses, LTP and LTD coincide, respectively, with an increase or shrinkage in spine size, which suggested that spine morphology might be linked to synaptic plasticity (Tada and Sheng, 2006). Our finding that the synaptic PSD length and spine head/neck ratio were not substantially changed by temporally increasing or decreasing cofilin activity (Fig. $8 A, D$ ) suggests that the effects of $\mathrm{ADF} /$ cofilin on AMPAR synaptic trafficking were not attributed to their action on the spine structure. Our analyses of AMPAR synaptic surface recruitment and spine size indicate that these two events are not directly coupled, which is consistent with an emerging opinion on the decoupling between spine size and synaptic strength (Cingolani and Goda, 2008). The disassociation of synaptic efficacy (physiology) and spine size has also been suggested in other studies. Loss of $\mathrm{n}$-cofilin in forebrain leads to accumulation of synaptic F-actin content, increased synapse density in the hippocampus, and enlargement of dendritic spines. However, cofilin knock-out mice showed slowed AMPAR motility, and impaired LTP and associative learning (Rust et al., 2010). Moreover, limk-1 knock-out mice showed smaller spines, but enhanced LTP (Meng et al., 2002). Cdk5 activity has been implicated with the formation and strengthening of new synapses, whereas inhibition of Cdk5 activity in the hippocampus has been shown to facilitate the extinction of contextual fear (Fischer et al., 2005; Fu et al., 2007; Sananbenesi et al., 2007). Our study provided another example for the disassociation of synaptic function and spine size regulated by actin dynamics.

In this study, we found that memory extinction induced a temporal activation of cofilin, which stimulated GluA1 and GluA2 translocation to synapse, and recruitment to postsynaptic membrane. Manipulating cofilin activity could alter the extinction process, which was mediated by AMPAR synaptic trafficking. Finally, we showed extinction triggered modifications of synaptic physiology and spine morphology are independent processes. Understanding the actin dynamics regulating the relationship between synaptic physiological function (number of synaptic receptors) and spine structure (spine size and density) is crucial to our comprehension of the mechanism of memory process.

\section{References}

Adams MM, Shah RA, Janssen WG, Morrison JH (2001) Different modes of hippocampal plasticity in response to estrogen in young and aged female rats. Proc Natl Acad Sci U S A 98:8071-8076. CrossRef Medline

Agnew BJ, Minamide LS, Bamburg JR (1995) Reactivation of phosphory- 
lated actin depolymerizing factor and identification of the regulatory site. J Biol Chem 270:17582-17587. CrossRef Medline

Aizawa H, Wakatsuki S, Ishii A, Moriyama K, Sasaki Y, Ohashi K, SekineAizawa Y, Sehara-Fujisawa A, Mizuno K, Goshima Y, Yahara I (2001) Phosphorylation of cofilin by LIM-kinase is necessary for semaphorin 3A-induced growth cone collapse. Nat Neurosci 4:367-373. CrossRef Medline

Anggono V, Huganir RL (2012) Regulation of AMPA receptor trafficking and synaptic plasticity. Curr Opin Neurobiol 22:461-469. CrossRef Medline

Aunis D, Bader MF (1988) The cytoskeleton as a barrier to exocytosis in secretory cells. J Exp Biol 139:253-266. Medline

Bamburg JR (1999) Proteins of the ADF/cofilin family: essential regulators of actin dynamics. Annu Rev Cell Dev Biol 15:185-230. CrossRef Medline

Barrett D, Shumake J, Jones D, Gonzalez-Lima F (2003) Metabolic mapping of mouse brain activity after extinction of a conditioned emotional response. J Neurosci 23:5740-5749. Medline

Berman DE, Hazvi S, Stehberg J, Bahar A, Dudai Y (2003) Conflicting processes in the extinction of conditioned taste aversion: behavioral and molecular aspects of latency, apparent stagnation, and spontaneous recovery. Learn Mem 10:16-25. CrossRef Medline

Bernstein BW, Bamburg JR (2010) ADF/cofilin: a functional node in cell biology. Trends Cell Biol 20:187-195. CrossRef Medline

Bi AL, Wang Y, Li BQ, Wang QQ, Ma L, Yu H, Zhao L, Chen ZY (2010) Region-specific involvement of actin rearrangement-related synaptic structure alterations in conditioned taste aversion memory. Learn Mem 17:420-427. CrossRef Medline

Bramham CR (2008) Local protein synthesis, actin dynamics, and LTP consolidation. Curr Opin Neurobiol 18:524-531. CrossRef Medline

Carlisle HJ, Kennedy MB (2005) Spine architecture and synaptic plasticity. Trends Neurosci 28:182-187. CrossRef Medline

Carlisle HJ, Manzerra P, Marcora E, Kennedy MB (2008) SynGAP regulates steady-state and activity-dependent phosphorylation of cofilin. J Neurosci 28:13673-13683. CrossRef Medline

Chen LY, Rex CS, Casale MS, Gall CM, Lynch G (2007) Changes in synaptic morphology accompany actin signaling during LTP. J Neurosci 27:5363-5372. CrossRef Medline

Cingolani LA, Goda Y (2008) Actin in action: the interplay between the actin cytoskeleton and synaptic efficacy. Nat Rev Neurosci 9:344-356. CrossRef Medline

Conboy L, Sandi C (2010) Stress at learning facilitates memory formation by regulating AMPA receptor trafficking through a glucocorticoid action. Neuropsychopharmacology 35:674-685. CrossRef Medline

Davis M, Ressler K, Rothbaum BO, Richardson R (2006) Effects of D-cycloserine on extinction: translation from preclinical to clinical work. Biol Psychiatry 60:369-375. CrossRef Medline

Eitzen G (2003) Actin remodeling to facilitate membrane fusion. Biochim Biophys Acta 1641:175-181. CrossRef Medline

Endo M, Ohashi K, Sasaki Y, Goshima Y, Niwa R, Uemura T, Mizuno K (2003) Control of growth cone motility and morphology by LIM kinase and slingshot via phosphorylation and dephosphorylation of cofilin. J Neurosci 23:2527-2537. Medline

Fischer A, Sananbenesi F, Schrick C, Spiess J, Radulovic J (2004) Distinct roles of hippocampal de novo protein synthesis and actin rearrangement in extinction of contextual fear. J Neurosci 24:1962-1966. CrossRef Medline

Fischer A, Sananbenesi F, Pang PT, Lu B, Tsai LH (2005) Opposing roles of transient and prolonged expression of p25 in synaptic plasticity and hippocampus-dependent memory. Neuron 48:825-838. CrossRef Medline

Fu WY, Chen Y, Sahin M, Zhao XS, Shi L, Bikoff JB, Lai KO, Yung WH, Fu AK, Greenberg ME, Ip NY (2007) Cdk5 regulates EphA4-mediated dendritic spine retraction through an ephexin1-dependent mechanism. Nat Neurosci 10:67-76. CrossRef Medline

Fukazawa Y, Saitoh Y, Ozawa F, Ohta Y, Mizuno K, Inokuchi K (2003) Hippocampal LTP is accompanied by enhanced F-actin content within the dendritic spine that is essential for late LTP maintenance in vivo. Neuron 38:447-460. CrossRef Medline

Gu J, Lee CW, Fan Y, Komlos D, Tang X, Sun C, Yu K, Hartzell HC, Chen G, Bamburg JR, Zheng JQ (2010) ADF/cofilin-mediated actin dynamics regulate AMPA receptor trafficking during synaptic plasticity. Nat Neurosci 13:1208-1215. CrossRef Medline
Hollingsworth EB, McNeal ET, Burton JL, Williams RJ, Daly JW, Creveling CR (1985) Biochemical characterization of a filtered synaptoneurosome preparation from guinea pig cerebral cortex: cyclic adenosine $3^{\prime}: 5^{\prime}$ monophosphate-generating systems, receptors, and enzymes. J Neurosci 5:2240-2253. Medline

Hotulainen P, Hoogenraad CC (2010) Actin in dendritic spines: connecting dynamics to function. J Cell Biol 189:619-629. CrossRef Medline

Hou YY, Lu B, Li M, Liu Y, Chen J, Chi ZQ, Liu JG (2009) Involvement of actin rearrangements within the amygdala and the dorsal hippocampus in aversive memories of drug withdrawal in acute morphine-dependent rats. J Neurosci 29:12244-12254. CrossRef Medline

Joels G, Lamprecht R (2010) Interaction between N-ethylmaleimidesensitive factor and GluR2 is essential for fear memory formation in lateral amygdala. J Neurosci 30:15981-15986. CrossRef Medline

Kullmann DM (2003) Silent synapses: what are they telling us about longterm potentiation? Philos Trans R Soc Lond B Biol Sci 358:727-733. CrossRef Medline

Magariños AM, Li CJ, Gal Toth J, Bath KG, Jing D, Lee FS, McEwen BS (2011) Effect of brain-derived neurotrophic factor haploinsufficiency on stress-induced remodeling of hippocampal neurons. Hippocampus 21: 253-264. CrossRef Medline

Mantzur L, Joels G, Lamprecht R (2009) Actin polymerization in lateral amygdala is essential for fear memory formation. Neurobiol Learn Mem 91:85-88. CrossRef Medline

Matus A (2000) Actin-based plasticity in dendritic spines. Science 290:754758. CrossRef Medline

Meng Y, Zhang Y, Tregoubov V, Janus C, Cruz L, Jackson M, Lu WY, MacDonald JF, Wang JY, Falls DL, Jia Z (2002) Abnormal spine morphology and enhanced LTP in LIMK-1 knock-out mice. Neuron 35:121-133. CrossRef Medline

Milad MR, Quirk GJ (2002) Neurons in medial prefrontal cortex signal memory for fear extinction. Nature 420:70-74. CrossRef Medline

Miller G (2004) Forgetting and remembering: learning to forget. Science 304:34-36. CrossRef Medline

Moga DE, Shapiro ML, Morrison JH (2006) Bidirectional redistribution of AMPA but not NMDA receptors after perforant path simulation in the adult rat hippocampus in vivo. Hippocampus 16:990-1003. CrossRef Medline

Myers KM, Davis M (2002) Behavioral and neural analysis of extinction. Neuron 36:567-584. CrossRef Medline

Paxions G, Watson C (1996) The rat brain in stereotaxic coordinates, Ed 3. New York: Academic.

Rust MB, Gurniak CB, Renner M, Vara H, Morando L, Görlich A, SassoèPognetto M, Banchaabouchi MA, Giustetto M, Triller A, Choquet D, Witke W (2010) Learning, AMPA receptor mobility and synaptic plasticity depend on n-cofilin-mediated actin dynamics. EMBO J 29:1889-1902. CrossRef Medline

Sananbenesi F, Fischer A, Wang X, Schrick C, Neve R, Radulovic J, Tsai LH (2007) A hippocampal Cdk5 pathway regulates extinction of contextual fear. Nat Neurosci 10:1012-1019. CrossRef Medline

Tada T, Sheng M (2006) Molecular mechanisms of dendritic spine morphogenesis. Curr Opin Neurobiol 16:95-101. CrossRef Medline

Toda S, Shen HW, Peters J, Cagle S, Kalivas PW (2006) Cocaine increases actin cycling: effects in the reinstatement model of drug seeking. J Neurosci 26:1579-1587. CrossRef Medline

Van Troys M, Huyck L, Leyman S, Dhaese S, Vandekerkhove J, Ampe C (2008) Ins and outs of ADF/cofilin activity and regulation. Eur J Cell Biol 87:649-667. CrossRef Medline

Villasana LE, Klann E, Tejada-Simon MV (2006) Rapid isolation of synaptoneurosomes and postsynaptic densities from adult mouse hippocampus. J Neurosci Methods 158:30-36. CrossRef Medline

Yao Y, Kelly MT, Sajikumar S, Serrano P, Tian D, Bergold PJ, Frey JU, Sacktor TC (2008) PKM zeta maintains late long-term potentiation by $\mathrm{N}$-ethylmaleimide-sensitive factor/GluR2-dependent trafficking of postsynaptic AMPA receptors. J Neurosci 28:7820-7827. CrossRef Medline

Yu H, Wang Y, Pattwell S, Jing D, Liu T, Zhang Y, Bath KG, Lee FS, Chen ZY (2009) Variant BDNF Val66Met polymorphism affects extinction of conditioned aversive memory. J Neurosci 29:4056-4064. CrossRef Medline

Yuen EY, Liu W, Kafri T, van Praag H, Yan Z (2010) Regulation of AMPA receptor channels and synaptic plasticity by cofilin phosphatase slingshot in cortical neurons. J Physiol 588:2361-2371. CrossRef Medline 
Zhou Q, Xiao M, Nicoll RA (2001) Contribution of cytoskeleton to the internalization of AMPA receptors. Proc Natl Acad Sci U S A 98:1261-1266. CrossRef Medline

Zhou Z, Hu J, Passafaro M, Xie W, Jia Z (2011) GluA2 (GluR2) regulates metabotropic glutamate receptor-dependent long-term depression through $\mathrm{N}$-cadherin-dependent and cofilin-mediated actin reorganization. J Neurosci 31:819-833. CrossRef Medline

Zushida K, Sakurai M, Wada K, Sekiguchi M (2007) Facilitation of extinction learning for contextual fear memory by PEPA: a potentiator of AMPA receptors. J Neurosci 27:158-166. CrossRef Medline 